\title{
FORMAÇÃO DE CONCEITOS DE LEITURA: RELAÇÃO COM A COGNIÇÃO E OS PROCESSOS DE SIGNIFICAÇÃO
}

\author{
Dioni Maria dos Santos Paz
}

\section{RESUMO}

Este artigo pretende ser um instrumento de reflexão sobre a formação de conceitos de leitura de futuros profissionais e formadores, envolvidos com a tarefa de ensinar leitura em sala de aula, pois compreendemos a formação acadêmica como mais uma fase formativa do ser humano que, em interação com os demais indivíduos sociais, cria as diferentes possibilidades de construção e reconstrução de seus conceitos sobre as coisas do mundo. Tal constatação no faz repensar a leitura como fator primordial na construção do indivíduo como sujeito da história e da cultura.

\section{INTRODUÇÃO}

Os desafios encontrados na área do ensino de leitura no Brasil são inúmeros, basta ver os resultados das provas do Exame Nacional do Ensino Médio (ENEM), realizadas nos últimos anos. Essa é uma realidade que nos obriga refletir a respeito da formação de conceitos de leitura adquiridos por sujeitos responsáveis pelo ensino/aprendizagem de leitura em sala de aula. Talvez, o grande desafio seja as concepções de leitura dos professores e futuros professores, adquiridos durante a vida escolar e acadêmica.

Uma das saídas para esse impasse parece ser o uso da psicolingüística como um ponto interdisciplinar entre a psicologia cognitiva e a lingüística, com o propósito de investigar a interação entre pensamento e linguagem. Porém, é um desafio questionar no indivíduo escolarizado ou pouco-escolarizado, a formação de conceitos de qualquer natureza. No entanto, é um caminho compreender quais são esses processos cognitivos elaborados pelos indivíduos ao realizarem determinadas leituras.

\section{RELAÇÕES ENTRE CULTURA E COGNIÇÃO}

Pesquisas feitas mostram-nos que, nos últimos anos, o funcionamento cognitivo da mente tem sido objeto de estudos da epistemologia, da psicologia ou das ciências cognitivas a partir de diferentes teorias. Essa realidade tem trazido muitas contribuições para a compreensão dos processos do pensamento e a formulação de 
conceitos e modelos de aprendizagem. Por sua vez, os estudos sobre o funcionamento cognitivo de pessoas em culturas diferentes ampliaram os métodos experimentais e as possibilidades de construção de explicações e generalizações.

Sabe-se também que a linguagem e a tese de uma mediação simbólica entre os processos cognitivos e o mundo sócio-cultural sempre estiveram integradas aos trabalhos sócio-interacionais. Esses estudos são responsáveis pela manutenção da hipótese essencial: a cognição individual constitui-se pela interiorização das formas sociais das interações humanas. Portanto, qualquer investigação que pretenda enfocar as relações entre pensamento e linguagem ou pensamento e cultura terá que conhecer a obra vygotskyana.

Uma premissa de Vygotsky (1998) é de que o funcionamento mental no ser humano é oriundo de processos sociais, pois não se pode estudar o comportamento do indivíduo em contexto isolado, mas em interação com outros indivíduos. Afirma também que esse processo de interação social é responsável por transformações no comportamento, pois os processos sociais e psicológicos são moldados por formas de mediação e se dão a partir da transformação de objetos em signos culturais.

Por sua vez, D'Andrade (1995) construiu um modelo de processamento cognitivo da mente comum, que consiste de um esquema cognitivo composto por percepções, crenças, sentimentos, desejos, intenções e decisões, compartilhados intersubjetivamente por determinado grupo social. Esse esquema é uma forma de entender como formações sócio-culturais compartilhadas servem de apoio às relações e ações sociais. "O modelo funciona basicamente, na forma de um circuito de alimentação e processamento de idéias e qualidades de idéias, partindo do ato perceptivo, passando pela cognição em seus diversos aspectos e desembocando na conduta consciente". ( Richter, Moreira e Souza 2003:163)

Dessa forma, a análise, a interpretação e a descrição dos mecanismos de formação de conceitos, segundo uma abordagem sócio-cognitiva, deve fazer uso desse modelo de processamento cognitivo de D'Andradre (1995) como também dos estudos sobre formação de conceitos numa perspectiva sócio-cultural de Vygotsky (1998). 


\title{
3. RELAÇÕES ENTRE LINGUAGEM E COGNIÇÃO
}

As relações entre cognição e discurso ou pensamento e linguagem tornaramse objeto de estudo de várias disciplinas derivadas da lingüística. Essa questão faznos refletir sobre a formação de conceitos de leitura e as palavras que a designam, ao mesmo tempo que revela a complexidade das relações entre conceitos e palavras.

Para Vygotsky (1993:104),

\begin{abstract}
uma palavra sem significado é um som vazio; o significado, portanto, é um critério da "palavra", seu componente indispensável. (...) do ponto de vista da psicologia, o significado poderia ser visto como uma generalização ou um conceito. $E$ como as generalizações ou os conceitos são inegavelmente atos de pensamento, podemos considerar o significado como um fenômeno do pensamento.
\end{abstract}

Tais colocações nos levam a crer que o significado das palavras é um fenômeno do pensamento (verbal) ou da significação - uma união da palavra com o pensamento. Por outro lado, a certeza de que o significado das palavras evolui, mostra-nos a natureza dinâmica do significado. Portanto, a principal idéia dessa assertiva é que a relação entre o pensamento e a palavra é um processo num movimento de vaivém.

Ciências ligadas à área da cognição, defendem como primordial estudos que envolvam a organização conceitual, a linguagem e a sociedade. Para Oliveira (1999:101),

\begin{abstract}
um conceito não é uma entidade isolada identificada por um conjunto de propriedades, um conceito também constitui-se das relações com outros conceitos, que formam redes ou teorias, as quais, por sua vez, têm cada conceito como elemento constitutivo.
\end{abstract}

Concordando com Vygotsky (1998), sobre a abordagem histórico-cultural em psicologia, Oliveira reforça que existem três dimensões nos conceitos vygotskyanos. A primeira dimensão é a idéia de libertação dos homens mediante o processo de abstração e generalização possibilitado pela linguagem. É a diferença que existe entre os seres humanos e os outros animais, pois os homens refletem a realidade, através da experiência, baseada na função da linguagem como reflexo da realidade. Então a palavra é um ato verbal do pensamento. A segunda dimensão é a dos conceitos como um sistema complexo de inter-relações. Essa visão trata melhor a complexidade da organização conceitual na mente humana. Trabalha com relações e estruturas 
aplicáveis a todas as espécies de conceitos (esfera da ciência, esfera da vida cotidiana e do senso comum). Nessa concepção, os conceitos estão organizados em um todo estruturado, em uma rede de significados, em que há relações entre os elementos. $A$ terceira dimensão é a dos conceitos não como entidades estáveis, mas como processos de construção de significação entre os seres humanos, através da interação. É através da interação humana com objetos de ação e de conhecimento, com signos e significados culturais que se constrói significados mediante processos de negociações interpessoais.

\section{RELAÇÃO DA COGNIÇÃO COM A LEITURA}

Os novos paradigmas que elucidam a questão do processo ensino/aprendizagem de leitura são frutos das pesquisas realizadas em várias áreas do conhecimento, especialmente em lingüística, psicolingüística, sociolingüística, psicologia cognitiva e teoria da recepção. A partir desses estudos, a leitura passou a ser vista como produção mediada pelo texto em seu processo de significação e de construção do conhecimento. "Trata-se de uma concepção que envolve o indivíduo, enquanto ser psicológico, que desenvolve suas habilidades cognitivas, e ser social, inserido em determinadas práticas histórico-sociais de leitura." (MEC,1996:20).

Segundo o texto citado, uma concepção de leitura envolve a interação com o vasto universo de conhecimento do aluno, incluindo seu conhecimento prévio, pois o sentido não está pronto no texto. Ele é produzido a partir de articulações e atividades que levem o aluno a se inserir no mundo da linguagem do texto. Esse fundamento, poderá construir um leitor crítico, capaz de se posicionar diante de fatos e usar essa habilidade para se posicionar no mundo e adquirir uma compreensão do mundo que o cerca.

Pode-se reconhecer que essa abordagem está calcada na teoria vygotskyana que permite levar o aluno e o professor a conceberem a leitura como processo de construção do sentido entre o leitor (ser individual e social), o texto (produto individual, determinado histórica e socialmente) e o autor (sujeito condicionado historicamente) e as práticas sociais e culturais nas quais ocorre essa interlocução. 
Concordando com Vygotsky, Kleiman (1989) afirma que a concepção de leitura enquanto interação assume que o sentido não é algo pronto no texto, mas é produzido pelo leitor a partir de seus conhecimentos prévios, de seus objetivos e de sua ação sobre a materialidade lingüística presente no texto.

\section{INTERAÇÃO NA LEITURA: PROCESSOS DE INFORMAÇÃo E CONCEITUAÇÃO}

Os mecanismos envolvidos no processo de leitura nem sempre são conhecidos ou considerados por aqueles que estão envolvidos com o ensino/aprendizagem da compreensão de textos. Ter consciência dos fatores cognitivos que estão envolvidos nesse processo é de extrema relevância e instrumento de auxílio para o professor.

O fator escolaridade, nesses estudos, certamente está relacionado com o nível de qualidade nos processos de informação e elaboração de conceitos propostos por teóricos das áreas da cognição.

Segundo Farnhan-Diggory (1992), há dois tipos básicos de processamento de informação: top-down (descendente) e o botton-up (ascendente). O primeiro faz uma leitura dedutiva, não-linear, das informações. Sua direção é da macro para a microestrutura do texto e da função para a forma. O segundo faz uma leitura indutiva, linear das informações, construindo o significado através da análise e síntese do significado das partes.

A psicologia cognitivista enfatiza a abordagem descendente, em seus modelos de aprendizagem. Tal abordagem privilegia o leitor que apreende rapidamente as idéias gerais e essenciais do texto, é fluente, mas deve ter cuidado para não fazer excessos de adivinhações do significado geral. Conseqüentemente, é o tipo de leitor que faz mais uso de seu conhecimento prévio do que da informação propriamente dita do texto. O segundo tipo de leitor é aquele que enfatiza o processo ascendente, construindo o significado, principalmente, com base nos dados do texto, fazendo pouca leitura ou quase nada nas entrelinhas do texto, detendo-se vagarosamente nas palavras e tendo dificuldade para sintetizar as idéias mais importantes.

No processo descendente, o leitor estimula os chamados pacotes de esquemas, isto é, conhecimentos já estruturados, acompanhados de instruções para 
determinado uso. Esses pacotes de esquemas ligam-se a outros esquemas ou subesquemas e acionam uma rede de inter-relações que são ativadas no ato da leitura, produzindo significações e situações novas, da mesma forma que um indivíduo é capaz de entender e produzir sentenças nunca antes ouvidas.

Segundo Kato (1995:41),

fazendo-se uma analogia com modelos estritamente lingüísticos e psicolingüísticos, podemos dizer que o pacote de conhecimento está para a gramática da competência assim como as instruções para seu uso estão para as estratégias psicolingüísticas que determinam a compreensão e a produção de sentenças.

O processamento descendente (top-down) pode ocorrer no nível da palavra, da frase ou do texto. No nível da palavra, o leitor pode seguir algumas pistas: letras iniciais, ou finais, ou ainda a extensão da palavra (input visual) bem como pode acionar o seu léxico mental e as regras de composição grafêmica e de formação de palavras. Por exemplo: feliz, infeliz, felizmente, infelizmente. Como vemos, a possibilidade de leitura descendente está relacionada à familiaridade da palavra com nosso léxico mental.

No nível da frase, o processamento descendente segue critérios semânticos vinculados a esquemas já conhecidos. Por exemplo: Casaco de homem de vaca. É possível, numa abordagem descendente, apenas a segmentação casaco de homem/ de vaca, porque a segmentação codifica uma situação mais aceitável, remetendo a um esquema conhecido por muitos leitores.

No nível do texto, o leitor usa esquemas acionados por palavras ou expressões temáticas e também esquemas que codificam estruturas retóricas. Vejamos um exemplo com a primeira estrofe (adaptada por mim) da canção Máscara negra, de Zé Kéti e Pereira Mattos.

\footnotetext{
Tanto riso, ó! Tanta alegria!

Mais de mil palhaços no salão

Arlequim está procurando pela Colombina

No meio da multidão.

Ele a encontrou chorando, vestida de preto

Carregando uma cruz.

(adaptação minha)
} 
No texto acima, arranjado para provocar um efeito instigante ao leitor, as expressões tanto riso, tanta alegria, palhaços, salão, Arlequim, Colombina fazem parte de uma temática que aciona o esquema relativo ao evento carnaval. Porém, as palavras chorando, vestida de preto, carregando uma cruz causam um inesperado que contradiz a expectativa do leitor que possui um conhecimento armazenado da cena descrita, pois no texto original a letra diz o seguinte: Arlequim está chorando pelo amor da Colombina no meio da multidão.

Para o leitor que não possui o esquema carnaval armazenado na memória, ou o conhecimento sobre o amor de Arlequim (personagem fictícia) por Colombina (personagem fictícia) que traiu seu amado no carnaval, a leitura pode passar a ser ascendente, desacelerando o ritmo da leitura, porém perderá muito na atribuição de significações.

Na medida em que a compreensão do inesperado acontece, os esquemas e as variáveis são preenchidas, constituindo-se em representação mental consciente. As informações passam a ser velhas e, estando no nível do consciente, possibilitam novas informações.

O processamento de leitura top-down que aciona esquemas já codificados assemelha-se à chamada concepção prototípica do significado, denominada pela psicóloga norte-americana Eleanor Rosch no início da década de 70.

A concepção prototípica faz parte dos processos cognitivos que fazem correlações com aspectos do processo de categorização, isto é, "quanto mais típico um caso - um exemplar ou um subconceito - mais rapidamente ele é categorizado, e menor é o número de erros". (Oliveira:1999:24) A leitura, nessa forma de processo, parte de um conceito codificado em termos de situações ou eventos típicos que instanciam esse conceito.

Sendo assim, "o leitor mais competente é aquele que faz mais adivinhações acertadas e que o leitor imaturo é aquele que faz uma leitura linear com pouca predição". (Kato, 1995:53).

Nesse sentido, a compreensão não se encontra pronta, mas em funcionamento constante e possível de ser ativada. Nessa perspectiva de leitura, ganham relevância 
a memória, a percepção, o raciocínio e a linguagem. Tal concepção reconhece que a leitura é um processo que começa no momento em que o cérebro recebe a informação visual e termina quando esta informação é associada aos conhecimentos prévios (experiências de mundo e de linguagem) que o leitor adquiriu. Podemos dizer que ganham força os conjuntos de relação cognitivas que se encontram armazenadas na mente, formando uma rede de informações que são acionadas e determinam a leitura.

\section{CONCLUSÃO}

O tipo de leitura assumido pelo professor permite definir uma concepção de leitor que vai ser originado desse ensino- aprendizagem. Portanto, se optarmos pelo conceito de leitura como um processo descendente (top-down), o leitor não é mais visto como um repetidor passivo, mas como um produtor de significados, pois estará acionando seu potencial criativo e seus conhecimentos prévios e inserindo-se no mundo sócio-cultural.

Isso é apenas um fragmento de uma concepção clara de leitura da qual os envolvidos durante o ato de ler poderão repensar. Ao professor competente e criativo, caberá a tarefa de articular atividades significativas que induzam o aluno a utilizar e desenvolver sua capacidade cognitiva e metacognitiva, já que tomará consciência do que faz e por que o faz.

Então, a leitura e a linguagem, compreendidas como lugar de interação humana e social, constituirão a si e ao sujeito não um conjunto de códigos e normas irrevogáveis, mas um trabalho (ação para transformar) social e sempre em curso. Portanto, se a aprendizagem da leitura quiser evoluir para o desenvolvimento do sujeito, seu aqui e agora tem de ser respeitado e valorizado. Seus conhecimentos prévios de mundo e de linguagem devem ser vistos não como síntese do passado, mas como proposta de contribuição para leituras futuras.

Dessa forma, a leitura sendo vista não como ato isolado de um indivíduo diante da escrita do outro indivíduo, supõe a imersão no contexto social da linguagem e da aprendizagem, através da interação com o outro. Leitor e autor, sujeitos com suas respectivas histórias de leituras de mundo, são responsáveis pela construção de 
transformações a partir da tomada de consciência da importância de ser cidadão no mundo e do mundo.

\section{BIBLIOGRAFIA}

BRASIL.MEC. Projeto pró-leitura na formação do professor. Brasília: MEC/SEF, 1996.

D'ANDRADE, Roy. A folk model of mind. In: Holland, D., Quinn,N. Cultural models in language \& thought. Cambridge: Cambridge University Press, 1995.

FARNHAM-DIGGORY, Sílvia. Cognitive process in education. New York: Harper Collins, 1992.

KATO, Mary. O aprendizado da leitura. São Paulo: Martins Fontes,1995.

KLEIMAN, Ângela. Texto e leitor: aspectos cognitivos da leitura. Campinas;

Pontes, 1989.

OLIVEIRA, Martha Kohl de. Vygotsky aprendizagem e desenvolvimento: um processo sócio-histórico. São Paulo: Scipione,1997.

OLIVEIRA, Marcos, Oliveira Marta (orgs). Investigações cognitivas: conceitos, linguagem e cultura. Porto Alegre: Artes Médicas, 1999.

VYGOTSKY, L. S. Pensamento e linguagem. 2 ed. São Paulo: Martins Fontes,1993.

VYGOTSKY, L. S. A formação social da mente: O desenvolvimento dos processos psicológicos superiores. "ed. São Paulo: Martins Fontes, 1998.

RICHTER, Marcos; Moreira, Tânia; Souza, Rosângela. A leitura de diários como prática social reflexiva . Expressão.CAL.UFSM. jan/jun/2003. 